\title{
Food habits of young Swedish and Norwegian vegetarians and omnivores
}

\author{
Christel L Larsson ${ }^{1, *}$, Kristin S Klock², Anne Nordrehaug Åstrøm²,3, Ola Haugejorden² \\ and Gunnar Johansson ${ }^{1}$ \\ 'Department of Food and Nutrition, Umeå University, SE-901 87 Umeå, Sweden: ${ }^{2}$ Department of Odontology - \\ Community Dentistry, University of Bergen, Aarstadveien 17, N-5003 Bergen, Norway: ${ }^{3}$ Centre for International \\ Health, University of Bergen, Armauer Hansen Building, N-5021 Bergen, Norway
}

Submitted 27 October 2000: Accepted 9 March 2001

\begin{abstract}
Objective: To determine the prevalence of vegetarianism and compare food habits among vegetarian and omnivorous adolescents in Sweden and Norway.

Design: Cross-sectional study by questionnaire in Sweden and Norway to gather information about food habits.

Setting: The municipalities of Umeå and Stockholm in Sweden, and Bergen in Norway.

Subjects: In total 2041 ninth-grade students (578 from Umeå, 504 from Stockholm and 959 from Bergen), mean age 15.5 years, were included. The response rate was 95\% in Umeå, 91\% in Stockholm and 83\% in Bergen.

Results: There was a significantly higher prevalence of vegetarianism in Umeå (15.6\%) than in Stockholm (4.8\%) and Bergen (3.8\%). Vegetarians generally wanted more information about a healthy diet and vegetarian females ate dietary supplements to prevent deficiencies more often than omnivorous females $(P<$ 0.01). The young male vegetarians more or less excluded animal products from their diet without changing their food frequency intake or modifying their dietary habits in other respects, while the young female vegetarians more often consumed vegetables and dietary supplements $(P<0.05)$. However, there was no difference between the intake of fruits/berries, alcoholic beverages, ice cream, sweets/chocolates and fast foods by vegetarians compared with omnivores.

Conclusions: There were three to four times more vegetarians in Umeå than in Stockholm and Bergen. The food habits of the young vegetarians differed from those of omnivorous adolescents and also in some respects from previously published comparative studies of vegetarians' and omnivores' food habits. It is uncertain whether the health benefits shown in previous studies on vegetarianism will be experienced by this young generation of vegetarians.
\end{abstract}

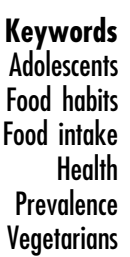

Adolescents

Food habits

intake

Prevalence

Vegetarians
Several studies have examined the nutritional effects of vegetarianism but few have studied the prevalence of vegetarians ${ }^{1}$. According to three different studies performed in Sweden in 1996, the prevalence of vegetarians was between $4.4 \%$ and $5.0 \%^{2}$ and according to a Norwegian study ${ }^{3}$ among 18-year-old Norwegians performed in 1993, 0.9\% of the adolescents studied were vegetarians. Recent studies show that vegetarian teenagers adopt a vegetarian diet for ideological rather than for health reasons ${ }^{4-7}$. Interviews with vegetarian adolescents, school matrons, school nurses and parents of vegetarians indicate that meat avoidance among teenagers in Sweden has become popular and that the life philosophy Straight Edge $^{2}$ and animal liberation organisations have had a strong influence on the beliefs of Swedish teenagers. Some of the young vegetarians have become vegetarian from a broad base of knowledge, while others have little understanding of the nutritional implications of various dietary practices. Concerns have been expressed among school matrons, school nurses and parents of vegetarians about the nutritional adequacy of the meatfree diet that some of the adolescents seem to eat, and also about a possible association between anorexia nervosa and vegetarianism ${ }^{8-10}$. However, to date, no study has been performed on these young vegetarians and it is not known whether their food habits differ from those of omnivorous adolescents in other respects than meat consumption. 
Several studies on the health benefits of vegetarian diets conclude that vegetarians have a lower mortality from ischaemic heart diseases ${ }^{11-13}$. Vegetarianism appears to result in health effects such as lower mean body mass index, lower blood pressure and lower serum cholesterol concentration not only because of the diet, but also because of other lifestyle factors. The food habits of vegetarians differ from those of omnivores not only with regard to the absence of meat, but also with regard to many other important aspects such as increased consumption of vegetables, fruits and nuts, which contributes to some of the health benefits of vegetarianism ${ }^{14,15}$. However, the health benefits not only depend on the food habits but also on the lifestyle that vegetarians choose. For example, a person choosing vegetarianism for mainly health reasons may be more intent on eating nutritious foods and also be more physically active and not smoke than a person choosing vegetarianism for mainly ethical reasons. The latter may, in a worst-case scenario, exclude animal products without replacing them with equally nutritious vegetarian products.

The aim of this investigation was to determine the prevalence of vegetarianism and compare the food habits of different vegetarian and omnivorous adolescents in Sweden and Norway.

\section{Subjects and methods}

\section{Subjects}

This study was performed in three cities, Umeå in northeastern Sweden (104 000 inhabitants), Stockholm in mideastern Sweden (1.8 million inhabitants) and Bergen in western Norway (220 000 inhabitants). Lists of municipal senior secondary schools were obtained from the education authorities and all students were recruited during the autumn of 1996. The Swedish subjects (with a mean age of 15.5 years) were recruited by random selection of ninth-grade classes of municipal senior secondary schools. Classes with more than 15 students, rather than individuals, were the sampling units since the school setting simplified data collection and improved the probability of a high response rate. Students who were absent on the day of the survey were given an opportunity to complete the questionnaire on another day. The questionnaire was handed to 608 students out of 1151 (sampling fraction 53\%) in Umeå and 554 students out of 5407 (sampling fraction 10\%) in Stockholm. In total 1082 Swedish adolescents completed the questionnaire: 578 (95\%) students from 22 classes and nine schools in Umeå, and 504 (91\%) from 22 classes and 17 schools in Stockholm. In both Umeå and Stockholm all classes selected and all students present on the day of the survey were willing to participate in the study. In Bergen a random sample of 11 schools was drawn from a total of 24 schools in the municipality. Three schools refused to participate and were replaced by randomly selecting three new schools from the remaining 13. A questionnaire was distributed to 1152 students out of 2239 (sampling fraction 51\%) in Bergen. In total 959 (83\%) Norwegian adolescents (15-16 years old) from 43 classes and 11 schools in Bergen completed the questionnaire. Altogether 2041 Swedish and Norwegian ninth-grade students participated in the study.

In Sweden the central school administrations, the principal of each school, the teachers and the pupils in the classes concerned were informed of and gave their consent to the study. In Norway permission to conduct the study was obtained from the education authorities, and teachers and pupils in the schools concerned were informed of the study and gave their consent. The study was approved by the Research Ethics Committee of the Medical Faculty, Umeå University, Umeå, Sweden.

\section{Questionnaire}

A pilot study was performed in spring of 1996 with 44 ninth-grade students from a suburb of Umeå and 30 ninthgrade students in Bergen. The questionnaire was then revised to prevent misunderstandings. The students were asked to complete the questionnaire in the classroom. The respondents were given the opportunity to ask questions if anything on the questionnaire was unclear, and the completed forms were collected at the end of the session. The present paper reports the dietary results of the questionnaire while results concerning lifestyle characteristics will be reported later. In the present article 45 food habit questions from the Swedish and 35 questions from the Norwegian questionnaire (with 35 identical questions) are presented. Responses to 12 questions concerning attitudes, dietary knowledge and meal habit characteristics are presented in Tables 2 and 3, and responses to 33 questions concerning frequency consumption of different food items are presented in Table 4. The questionnaire included both quantitative and qualitative questions. The questions about frequency of consumption of different food items provided interval data. The participants indicated their average frequency of food consumption by marking one of the six frequency alternatives ranging from 'never/rarely' to 'several times a day'. To enable comparison between frequencies of consumption of foods that were more or less common in the diet, frequency responses were converted to consumption frequency of an item per month ${ }^{15}$. For example, a response of ' $2-4$ times/week (3 times/week)' was converted to ' 12 times/month'. A subject's answers were rejected if it was obvious that the respondent had not answered seriously, for instance if they had systematically given maximum frequency by drawing a line through the maximum frequency answer to all questions instead of marking each answer individually. However, this was not common and only happened about 10 times, in the food habit section.

Answers to the food frequency part of the questionnaire 
Table 1 Prevalence of vegetarianism in adolescents in Umeå and Stockholm, Sweden, and Bergen, Norway, eating various types of vegetarian diet in 1996

\begin{tabular}{|c|c|c|c|c|c|c|c|c|c|}
\hline \multirow[b]{3}{*}{ Type of vegetarian diet } & \multicolumn{9}{|c|}{ Prevalence (\%) } \\
\hline & \multicolumn{3}{|c|}{ Umeå* $^{*}$} & \multicolumn{3}{|c|}{ Stockholm† } & \multicolumn{3}{|c|}{ Bergen $\ddagger$} \\
\hline & $\begin{array}{c}\text { Males } \\
(n=263)\end{array}$ & $\begin{array}{l}\text { Females } \\
(n=293)\end{array}$ & $\begin{array}{c}\text { Total } \\
(n=578)\end{array}$ & $\begin{array}{c}\text { Males } \\
(n=253)\end{array}$ & $\begin{array}{l}\text { Females } \\
(n=244)\end{array}$ & $\begin{array}{c}\text { Total } \\
(n=504)\end{array}$ & $\begin{array}{c}\text { Males } \\
(n=501)\end{array}$ & $\begin{array}{l}\text { Females } \\
(n=451)\end{array}$ & $\begin{array}{c}\text { Total } \\
(n=959)\end{array}$ \\
\hline Vegan & 1.1 & 5.5 & 3.3 & 0.4 & 0.4 & 0.4 & 0 & 0.2 & 0.1 \\
\hline Lacto- and lacto-ovo-vegetarian & 4.6 & 13.0 & 8.8 & 1.2 & 2.5 & 1.8 & 1.4 & 1.3 & 1.4 \\
\hline Semi-vegetarian§ & 0.8 & 6.1 & 3.5 & 0.8 & 4.1 & 2.6 & 2.2 & 2.4 & 2.3 \\
\hline Total (all vegetarians) & 6.5 & 25.0 & 15.6 & 2.4 & 7.0 & 4.8 & 3.6 & 4.0 & 3.8 \\
\hline
\end{tabular}

* Information about gender was missing for 22 omnivores.

† Information about gender was missing for one semi-vegetarian and six omnivores.

$\ddagger$ Information about gender was missing for seven omnivores.

$\S$ Lacto-ovo-fish-vegetarian.

were used to classify subjects as either vegetarian or omnivore. Subjects were considered vegetarian if they had followed a vegetarian diet for the 12 months preceding the survey, and the questionnaire asked diet-related questions pertaining to that period of time. In this study vegetarians were defined as people falling into one of three different and commonly used categories, as follows ${ }^{16-18}$ :

1. Lacto-ovo-fish-vegetarians were defined as people eating vegetarian food and also dairy products and eggs as well as fish, but no meat or poultry, also called 'semi-vegetarians'.

2. Lacto-vegetarians and lacto-ovo-vegetarians were defined as people eating vegetarian food and including dairy products and sometimes eggs, but no meat, poultry or fish, hereafter called 'lacto-(ovo)vegetarians'.

3. Vegans were defined as people eating no animal products whatsoever.

All of the other subjects were defined as omnivores.

\section{Statistical analyses}

The Swedish data were entered into a computer with an optical mark reader using the form software Teleform (Cardiff Software Inc., San Marcos, CA, USA) and proofread twice by Larsson. The Norwegian data were manually entered into a computer and proofread once. SPSS version 9.0.1 (SPSS Pty Ltd, Chicago, IL, USA) was used for the statistical analyses. Data are presented according to diet and gender. For one vegetarian and 35 omnivores information about gender was missing. Comparisons between dietary groups were made separately for both genders and for each of the vegetarian groups compared with the omnivores by Pearson's chi-square, Fisher's exact test and Mann-Whitney non-parametric $U$ test. A two-tailed $P$-value of $<0.05$ was considered statistically significant.

\section{Results}

There were no differences in age, weight or height among the respondents with different diets or from different cities.

\section{Prevalence}

There was a higher prevalence of vegetarianism $(P<$ 0.01) in Umeå than in Stockholm and Bergen (Table 1). In Umeå lacto-(ovo)-vegetarians (8.8\%) were the most common type of vegetarian. In Stockholm and Bergen semi-vegetarians were the most common type of vegetarian. There was a higher percentage of females among vegetarians in Umeå and Stockholm $(P<0.01)$ but no gender difference was found in Bergen (Table 1).

\section{Attitudes, dietary knowledge and meal babits}

The young vegetarians generally wanted to find out more about healthy eating than did the omnivores and preferred to get the information from school and the media (Table 2). The male vegetarians obtained most of their knowledge related to diet from newspapers and magazines/brochures or from several different sources compared with male omnivores, who derived their information related to diet from their parents and the school. Female vegetarians perceived their own dietary intake to be inadequate more often than did female omnivores, and their main reason for taking dietary supplements was to prevent any nutritional deficiency. Some vegetarian females ate school lunch more often than omnivorous females, but there were also those who ate it less frequently (Table 3). The vegetarians ate breakfast and dinner less often with their families than did the omnivores, and more vegetarians than omnivores did not eat any breakfast at all.

Semi-vegetarians wanted more information about a healthy diet than did the omnivores. Semi-vegetarians also took supplements to prevent nutritional deficiencies or because they believed they had a deficiency (Table 2).

Lacto-(ovo)-vegetarians perceived their dietary intake to be inadequate. This group of vegetarians also wanted to find out more about healthy eating and more often preferred school or newspapers/magazines/brochures as their main source of information than did omnivores 
Table 2 Attitudes and dietary knowledge characteristics of vegetarian and omnivorous adolescents in 1996

\begin{tabular}{|c|c|c|c|c|c|c|c|c|}
\hline & \multicolumn{8}{|c|}{ Attitudes and dietary knowledge characteristics (\%)† } \\
\hline & \multirow[b]{2}{*}{$\begin{array}{c}\text { Male } \\
\text { vegetarians } \\
(n=41)\end{array}$} & \multirow[b]{2}{*}{$\begin{array}{c}\text { Male } \\
\text { omnivores } \\
(n=976)\end{array}$} & \multirow[b]{2}{*}{$\begin{array}{c}\text { Female } \\
\text { vegetarians } \\
(n=108)\end{array}$} & \multirow[b]{2}{*}{$\begin{array}{l}\text { Female } \\
\text { omnivores } \\
(n=880)\end{array}$} & \multirow[b]{2}{*}{$\begin{array}{c}\text { Omnivores } \\
\text { total } \\
(n=1891)\end{array}$} & \multicolumn{3}{|c|}{ Vegetarians } \\
\hline & & & & & & $\begin{array}{l}\text { Semi-veg. } \\
(n=55)\end{array}$ & $\begin{array}{l}\text { Lacto- } \\
\text { (ovo)-veg. } \\
(n=73)\end{array}$ & $\begin{array}{l}\text { Vegans } \\
(n=22)\end{array}$ \\
\hline Importance of diet to health $\ddagger$ & $(96 \%)^{\star \star}$ & $(98 \%)$ & $(100 \%)$ & $(99 \%)$ & $(99 \%)$ & $(100 \%)$ & $(98 \%)$ & $(100 \%)^{*}$ \\
\hline Very important & 77 & 75 & 84 & 83 & 79 & 88 & 78 & 90 \\
\hline Fairly important/of little importance & 9 & 23 & 15 & 15 & 19 & 12 & 19 & 0 \\
\hline Not important & 5 & 1 & 1 & 0 & 1 & 0 & 2 & 5 \\
\hline Do not know & 9 & 1 & 0 & 2 & 1 & 0 & 1 & 5 \\
\hline Perception of own dietary intake $\ddagger$ & $(96 \%)$ & $(98 \%)$ & $(100 \%)^{*}$ & $(98 \%)$ & $(99 \%)$ & $(100 \%)$ & $(98 \%)^{\star \star \star}$ & $(100 \%)$ \\
\hline Adequate & 27 & 36 & 23 & 19 & 28 & 18 & 24 & 33 \\
\hline Adequate on average & 50 & 49 & 39 & 56 & 52 & 58 & 34 & 38 \\
\hline Inadequate & 23 & 10 & 29 & 19 & 15 & 18 & 32 & 29 \\
\hline Do not know & 0 & 5 & 9 & 6 & 5 & 6 & 10 & 0 \\
\hline Informed about healthy eating $\neq$ & $(96 \%)$ & $(100 \%)$ & $(100 \%)$ & $(99 \%)$ & $(99 \%)$ & $(100 \%)$ & $(98 \%)$ & $(100 \%)$ \\
\hline Enough & 86 & 83 & 86 & 86 & 85 & 85 & 86 & 86 \\
\hline Not enough & 14 & 17 & 14 & 14 & 15 & 15 & 14 & 14 \\
\hline Main source of diet-related information $\ddagger$ & $(96 \%)^{\star \star \star}$ & $(98 \%)$ & $(97 \%)$ & $(98 \%)$ & $(98 \%)$ & $(91 \%)$ & $(98 \%)$ & $(95 \%)^{\star *}$ \\
\hline Parents & 27 & 41 & 37 & 41 & 41 & 39 & 36 & 25 \\
\hline School & 9 & 28 & 21 & 25 & 27 & 19 & 22 & 10 \\
\hline Newspapers/magazines/brochures & 23 & 3 & 17 & 12 & 8 & 16 & 15 & 30 \\
\hline Television, radio & 5 & 3 & 1 & 3 & 3 & 0 & 3 & 0 \\
\hline Several different sources & 36 & 14 & 14 & 9 & 11 & 16 & 17 & 25 \\
\hline Have not been given any information & 0 & 11 & 10 & 10 & 10 & 10 & 7 & 10 \\
\hline Wanting to be better informed about healthy eating & $(96 \%)^{\star \star}$ & $(98 \%)$ & $(100 \%)^{\star *}$ & $(98 \%)$ & $(96 \%)$ & $(100 \%)^{\star \star \star}$ & $(98 \%)^{\star \star}$ & $(100 \%)^{\star \star \star}$ \\
\hline Yes & 68 & 63 & 67 & 50 & 43 & 73 & 59 & 81 \\
\hline No & 32 & 37 & 33 & 50 & 57 & 27 & 41 & 19 \\
\hline Preferred main source of diet-related information $\ddagger$ & $(96 \%)^{\star \star}$ & $(98 \%)$ & $(100 \%)^{\star *}$ & $(99 \%)$ & $(91 \%)$ & $(100 \%)$ & $(98 \%)^{\star \star *}$ & $(100 \%)^{\star \star *}$ \\
\hline Parents & 9 & 12 & 10 & 9 & 11 & 12 & 12 & 0 \\
\hline School & 32 & 26 & 31 & 25 & 25 & 40 & 36 & 10 \\
\hline Newspapers/magazines/brochures & 9 & 4 & 22 & 11 & 7 & 12 & 20 & 28 \\
\hline Television, radio & 32 & 8 & 4 & 7 & 7 & 9 & 5 & 19 \\
\hline Several different sources & 4 & 5 & 10 & 6 & 6 & 6 & 3 & 29 \\
\hline Do not want more information & 14 & 45 & 23 & 42 & 44 & 21 & 24 & 14 \\
\hline Reason for taking dietary supplementsł & $(91 \%)$ & $(94 \%)$ & $(93 \%)^{\star \star \star}$ & $(95 \%)$ & $(94 \%)$ & $(91 \%)^{\star \star}$ & $(93 \%)^{\star \star \star}$ & $(95 \%)^{\star \star \star}$ \\
\hline I have, or I believe I have, a nutritional deficiency & 0 & 2 & 14 & 7 & 4 & 13 & 13 & 5 \\
\hline To prevent deficiency & 38 & 21 & 49 & 19 & 20 & 40 & 41 & 70 \\
\hline Do not know & 10 & 12 & 4 & 9 & 11 & 0 & 5 & 10 \\
\hline Do not take dietary supplements & 52 & 65 & 33 & 65 & 65 & 47 & 41 & 15 \\
\hline
\end{tabular}

† Response is given in \% and percentages in parentheses represent response rate to the question. Comparisons between dietary groups were made separately for both genders and for each of the vegetarian groups, as compared with the omnivores, by Pearson's chi-square (or Fisher's exact test for $2 \times 2$ tables).

† Results pertain to Umeå and Stockholm with a study population of 968 omnivores (447 females, 493 males and 28 no information about gender) and 114 vegetarians (90 females, 23 males and 1 no information about gender, or 33 semi-vegetarians, 60 lacto-(ovo)-vegetarians and 21 vegans)

Significantly different from omnivores $(P \leq 0.05)$.

*** Significantly different from omnivores $(P \leq 0.001)$. 
Table 3 Meal habit characteristics of vegetarian and omnivorous adolescents in 1996

\begin{tabular}{|c|c|c|c|c|c|c|c|c|}
\hline & \multicolumn{8}{|c|}{ Meal habit characteristics (\%)† } \\
\hline & \multirow[b]{2}{*}{$\begin{array}{c}\text { Male } \\
\text { vegetarians } \\
(n=41)\end{array}$} & \multirow[b]{2}{*}{$\begin{array}{c}\text { Male } \\
\text { omnivores } \\
(n=976)\end{array}$} & \multirow[b]{2}{*}{$\begin{array}{c}\text { Female } \\
\text { vegetarians } \\
(n=108)\end{array}$} & \multirow[b]{2}{*}{$\begin{array}{l}\text { Female } \\
\text { omnivores } \\
(n=880)\end{array}$} & \multirow[b]{2}{*}{$\begin{array}{c}\text { Omnivores } \\
\text { total } \\
(n=1891)\end{array}$} & \multicolumn{3}{|c|}{ Vegetarians } \\
\hline & & & & & & $\begin{array}{l}\text { Semi-veg. } \\
(n=55)\end{array}$ & $\begin{array}{l}\text { Lacto- } \\
\text { (ovo)-veg. } \\
(n=73)\end{array}$ & $\begin{array}{l}\text { Vegans } \\
(n=22)\end{array}$ \\
\hline Eat breakfast with the family & $(100 \%)^{\star \star}$ & $(99 \%)$ & $(100 \%)^{\star \star}$ & $(100 \%)$ & $(100 \%)$ & $(100 \%)$ & $(100 \%)^{\star \star \star}$ & $(100 \%)$ \\
\hline Daily & 29 & 38 & 27 & 30 & 34 & 27 & 26 & 32 \\
\hline 4-5 times/week & 7 & 10 & 7 & 10 & 10 & 9 & 7 & 5 \\
\hline 2-3 times/week & 27 & 20 & 19 & 23 & 21 & 26 & 14 & 36 \\
\hline Hardly ever & 27 & 30 & 36 & 33 & 32 & 29 & 39 & 23 \\
\hline Do not eat breakfast & 10 & 2 & 11 & 4 & 3 & 9 & 14 & 4 \\
\hline Eat cooked school mealł & $(100 \%)$ & $(99 \%)$ & $(100 \%)^{*}$ & $(100 \%)$ & $(100 \%)$ & $(100 \%)$ & $(100 \%)$ & $(100 \%)$ \\
\hline 5 times/week & 61 & 53 & 54 & 46 & 50 & 58 & 52 & 62 \\
\hline 4 times/week & 18 & 24 & 17 & 29 & 26 & 12 & 20 & 19 \\
\hline 3 times /week & 4 & 12 & 12 & 15 & 14 & 12 & 12 & 5 \\
\hline 2 times/week & 9 & 6 & 7 & 4 & 5 & 9 & 5 & 9 \\
\hline 1 time/week & 4 & 2 & 1 & 3 & 2 & 0 & 3 & 0 \\
\hline Never/rarely & 4 & 3 & 9 & 3 & 3 & 9 & 8 & 5 \\
\hline Reason for not eating school mealł & $(91 \%)$ & $(92 \%)$ & $(97 \%)$ & $(97 \%)$ & $(100 \%)$ & $(94 \%)$ & $(95 \%)$ & $(100 \%)^{\star \star \star}$ \\
\hline Eat school meal every day & 38 & 34 & 37 & 32 & 33 & 45 & 35 & 29 \\
\hline Do not like the food & 52 & 59 & 54 & 62 & 61 & 49 & 58 & 52 \\
\hline Lunch break too short & 0 & 2 & 2 & 1 & 1 & 3 & 0 & 5 \\
\hline Too noisy and busy in dining hall & 0 & 1 & 1 & 1 & 1 & 3 & 0 & 0 \\
\hline Queues too long & 0 & 3 & 1 & 1 & 2 & 0 & 2 & 0 \\
\hline Eat at home & 0 & 0 & 0 & 1 & 1 & 0 & 0 & 0 \\
\hline Not hungry & 10 & 1 & 5 & 2 & 1 & 0 & 5 & 14 \\
\hline Food eaten instead of school mealł & $(83 \%)$ & $(90 \%)$ & $(90 \%)$ & $(94 \%)$ & $(91 \%)$ & $(97 \%)$ & $(83 \%)$ & $(90 \%)^{\star \star}$ \\
\hline Eat school meal every day & 47 & 38 & 42 & 35 & 37 & 47 & 44 & 32 \\
\hline Cooked meal & 11 & 4 & 4 & 3 & 3 & 3 & 2 & 16 \\
\hline Hamburger/hot dog/kebab & 0 & 14 & 0 & 3 & 9 & 0 & 0 & 0 \\
\hline Cereals and sour milk/milk & 5 & 13 & 6 & 14 & 13 & 10 & 6 & 0 \\
\hline Sandwich & 11 & 9 & 17 & 21 & 14 & 25 & 14 & 5 \\
\hline Salad & 0 & 3 & 9 & 6 & 4 & 9 & 8 & 5 \\
\hline Fruit & 5 & 1 & 2 & 2 & 2 & 0 & 4 & 5 \\
\hline Candies & 11 & 8 & 5 & 6 & 7 & 0 & 4 & 21 \\
\hline Cookies & 5 & 1 & 1 & 1 & 2 & 0 & 4 & 0 \\
\hline Nothing & 5 & 9 & 14 & 9 & 9 & 6 & 14 & 16 \\
\hline Eat dinner with the family & $(100 \%)^{\star \star}$ & $(99 \%)$ & $(100 \%)^{\star \star \star}$ & $(100 \%)$ & $(99 \%)$ & $(100 \%)$ & $(100 \%)^{\star \star \star}$ & $(100 \%)^{\star \star \star}$ \\
\hline Usually daily & 68 & 73 & 60 & 72 & 73 & 74 & 62 & 36 \\
\hline 3-5 times/week & 17 & 21 & 19 & 20 & 20 & 15 & 19 & 27 \\
\hline$\leq 2$ times/week & 5 & 4 & 14 & 6 & 5 & 11 & 10 & 18 \\
\hline Never/rarely & 7 & 2 & 6 & 2 & 2 & 0 & 8 & 14 \\
\hline Do not eat dinner & 3 & 0 & 1 & 0 & 0 & 0 & 1 & 5 \\
\hline
\end{tabular}

† Response is given in \% and percentages in parentheses represent response rate to the question. Comparisons between dietary groups were made separately for both genders and for each of the vegetarian groups, as compared with the omnivores, by Pearson's chi-square (or Fisher's exact test for $2 \times 2$ tables).

‡ Results pertain to Umeå and Stockholm with a study population of 968 omnivores (447 females, 493 males and 28 no information about gender) and 114 vegetarians (90 females, 23 males and 1 no information about gender, or 33 semi-vegetarians, 60 lacto-(ovo)-vegetarians and 21 vegans).

* Significantly different from omnivores $(P \leq 0.05)$

** Significantly different from omnivores $(P \leq 0.01)$.

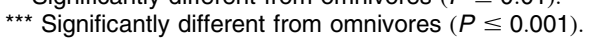

(Table 2). Furthermore, they took supplements to prevent nutritional deficiencies or because they believed they had a deficiency, ate breakfast with their family less frequently or not at all, and ate dinner with their family less frequently than the omnivores (Tables 2 and 3 ).

The vegans in this study believed that a healthy diet is important for maintaining good health. The vegans' main source of information related to diet were their parents, newspapers/magazines/brochures or several different sources of information. The vegans also wanted more information about a healthy diet. They consulted newspapers/magazines/brochures, television/radio or several different sources of information more often than did their omnivorous peers (Table 2). They also took supplements to prevent deficiencies. The reason they gave for not eating school meals was that they either did not like the food or were not hungry (Tables 2 and 3). Instead of the school meal the vegans ate another cooked meal, candies or nothing at all more often than the omnivores. They also ate dinner without company of family members or not at all more often than the omnivores.

\section{Frequency of food intake}

The vegetarian males in the present study largely excluded animal products but showed no other major differences from omnivorous males in food intake, except 
for eating margarine, ice cream, cake/cookies, and fried and barbecued food less often than did the omnivorous males (Table 4). On the other hand, the female vegetarians less often consumed such foods as potatoes, soft drinks, chips/peanuts, cakes/cookies, fried foods and barbecued food, and more often consumed rice/pasta, vegetables, coffee, tea, dietary supplements and microwave-heated food than did the female omnivores (Table 4). However, there was no difference between the female groups in consumption frequency of fruits/berries, alcoholic beverages, ice cream and sweets/chocolates, among other things.

Semi-vegetarians consumed fried potatoes, bread, margarine, soft drinks, chips/peanuts, ice cream, cakes/ cookies, fast foods and barbecued food less often than did their omnivorous peers (Table 4). However, they ate fish, vegetables and dietary supplements more often than the omnivores (Table 4).

Lacto-(ovo)-vegetarians consumed eggs, soft cheese, milk, sour milk/yoghurt, potatoes, fried potatoes, porridge, soft drinks, chips/peanuts, fried food and barbecued food less often than the omnivores (Table 4).

Vegans consumed potatoes, cereals, soft drinks, cakes/ cookies and barbecued food less often than did omnivores (Table 4). Finally, both lacto-(ovo)-vegetarians and vegans ate rice/pasta and vegetables, drank tea and took dietary supplements more often than their omnivorous peers (Table 4).

\section{Discussion}

\section{Subjects}

The participants of this study were drawn from the population of 15-16-year-old students in Umeå, Stockholm and Bergen. The ninth grade is compulsory in the Swedish and Norwegian school systems and the participation rates were very high, partly because this was a school-based study and all pupils present completed and returned the questionnaire in the classroom. Since classes or schools, rather than individuals, were used as sampling units there could be differences in ethical considerations between classes or schools. The 24 schools in Bergen ranged in size from one to five parallel classes of ninthgraders and since schools, rather than pupils, were randomly sampled, clustering probably reduced precision. However, the schools selected were distributed throughout the municipality and may therefore be regarded as representative of senior secondary schools in the municipality of Bergen.

The definition of the vegetarians and omnivores was based on the adolescents' response to food frequency questions and not on the adolescents' perception of their own eating behaviour. This was done because some people claim to be vegetarian when in actual fact they eat red meat or poultry on rare occasions, a practice which was not permitted by the definition of vegetarianism in the present study. In a 1998 study, Worsley and

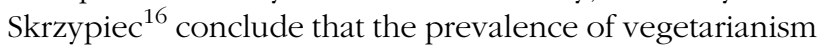
varies depending on whether the young subjects are asked if they are vegetarian (self-reported), or whether they are classified as vegetarian according to their selfreported food frequency intake. A self-defined vegetarianism was shown to give a higher prevalence figure than classification according to food intake. The approach to getting a more objective classification of vegetarians and omnivores in the present study made it inappropriate to ask questions related to vegetarianism and about reasons for becoming vegetarian. Results by gender and three different types of vegetarian diet are presented in the present study since the dietary intake may vary between these groups. However, data on the three study locations are not divided up into gender and different vegetarian diet groups because of too low statistical power (i.e. there are too few subjects in each category).

\section{Prevalence}

Few studies exist on the prevalence of vegetarianism and sometimes estimates are presented in the absence of definitions of different types of vegetarian diet. Furthermore, data are sometimes unreliable because of selfreported vegetarianism ${ }^{16}$. To be able to conclude that there is a change in the percentage of adolescents eating vegetarian food we need to compare our results with previous studies with a similar design. However, there are no such studies of this age group in Sweden or Norway. A study of Swedish senior secondary school students aged 16-20 years performed during the same year as this study (data collection in 1996) shows that $11.4 \%$ of the students ate vegetarian school lunches in Umeå and $7.1 \%$ did in Stockholm ${ }^{2}$. Assuming that the adolescents eating a vegetarian school lunch in that study ${ }^{2}$ were vegetarians, the present study of 15-16-year-old students also found a higher prevalence of vegetarians in Umeå (15.6\%) than in Stockholm (4.8\%) (Table 1). A possible explanation for the high prevalence of vegetarianism in Umeå is the strong local influence of the Straight Edge philosophy and different animal liberation organisations, which advocate a vegetarian $\operatorname{diet}^{2}$. The results also showed that most vegetarians were females, a finding that is consistent with many other studies ${ }^{5,6,16}$. One possible reason for this may be that females are more concerned about their weight ${ }^{19}$. Another study of adolescents showed that vegetarians (81\% females) had a higher incidence of eating disorders than did omnivores ${ }^{4}$. A 1991 study reported that women overall appear to be more concerned about their health, as well as about the financial and moral aspects of meat consumption $^{20}$.

\section{Attitudes, dietary knowledge and meal habits}

Balanced nutrition is important for maintaining optimal health, normal growth and development, as well as preventing future chronic diseases ${ }^{21}$. This is especially 


\begin{tabular}{|c|c|c|c|c|c|c|c|c|}
\hline & \multicolumn{8}{|c|}{ Food item, times/month (\%)† } \\
\hline & \multirow[b]{2}{*}{$\begin{array}{c}\text { Male } \\
\text { vegetarians } \\
(n=41)\end{array}$} & \multirow[b]{2}{*}{$\begin{array}{c}\text { Male } \\
\text { omnivores } \\
(n=976)\end{array}$} & \multirow[b]{2}{*}{$\begin{array}{c}\text { Female } \\
\text { vegetarians } \\
(n=108)\end{array}$} & \multirow[b]{2}{*}{$\begin{array}{c}\text { Female } \\
\text { omnivores } \\
(n=880)\end{array}$} & \multirow[b]{2}{*}{$\begin{array}{c}\text { Omnivores } \\
\text { total } \\
(n=1891)\end{array}$} & \multicolumn{3}{|c|}{ Vegetarians } \\
\hline & & & & & & $\begin{array}{l}\text { Semi-veg. } \\
(n=55)\end{array}$ & $\begin{array}{l}\text { Lacto- } \\
\text { (ovo)-veg. } \\
(n=73)\end{array}$ & $\begin{array}{l}\text { Vegans } \\
(n=22)\end{array}$ \\
\hline Sausages & $0(95 \%)^{\star \star \star}$ & $5.7(96 \%)$ & $0(98 \%)^{\star \star \star}$ & $4.6(98 \%)$ & $5.2(97 \%)$ & $0(93 \%)^{\star \star \star}$ & $0(100 \%)^{\star \star \star}$ & $0(100 \%)^{\star \star \star}$ \\
\hline Pork chops/spare ribs/bacon & $0(100 \%)^{\star \star \star}$ & $5.5(97 \%)$ & $0(99 \%)^{\star \star \star}$ & $4.3(99 \%)$ & $4.9(98 \%)$ & $0(98 \%)^{\star \star \star}$ & $0(100 \%)^{\star \star \star}$ & $0(100 \%)^{* \star *}$ \\
\hline Poultry & $0(100 \%)^{\star \star \star}$ & $4.4(97 \%)$ & $0(98 \%)^{* \star \star}$ & 3.7 (99\%) & $4.1(98 \%)$ & $0(96 \%)^{\star * *}$ & $0(100 \%)^{\star \star \star}$ & $0(100 \%)^{\star \star \star}$ \\
\hline Fish & $2.5(98 \%)^{\star \star \star}$ & $5.9(96 \%)$ & $2.7(100 \%)^{\star \star \star}$ & $5.5(99 \%)$ & $5.7(98 \%)$ & $7.2(98 \%)^{\star}$ & $0(100 \%)^{\star \star \star}$ & $0(100 \%)^{\star \star \star}$ \\
\hline Seafood (except fish) & $0.4(98 \%)^{*}$ & $1.0(97 \%)$ & $0.4(97 \%)^{*}$ & $0.7(97 \%)$ & $0.8(97 \%)$ & $1.0(98 \%)$ & $0(96 \%)^{\star \star \star}$ & $0(100 \%)^{\star *}$ \\
\hline Eggs & $3.8(98 \%)^{\star \star}$ & $5.4(96 \%)$ & $3.2(97 \%)^{\star \star}$ & $4.2(99 \%)$ & $4.9(98 \%)$ & $4.3(96 \%)$ & $3.7(97 \%)^{\star \star}$ & $0(100 \%)^{\star \star \star}$ \\
\hline Cheese & $17(100 \%)$ & $17(97 \%)$ & $16(98 \%)^{\star \star}$ & $18(99 \%)$ & $18(98 \%)$ & $20(98 \%)$ & $18(99 \%)$ & $0(100 \%)^{* \star \star}$ \\
\hline Soft cheese & $6.4(95 \%)$ & $5.8(97 \%)$ & $3.3(99 \%)^{\star \star *}$ & $5.2(98 \%)$ & $5.5(97 \%)$ & $6.1(96 \%)$ & $3.9(99 \%)^{*}$ & $0(100 \%)^{\star \star \star}$ \\
\hline Milk & $35(100 \%)^{*}$ & $42(100 \%)$ & $28(100 \%)^{\star *}$ & $35(100 \%)$ & $39(100 \%)$ & $39(100 \%)$ & $32(100 \%)^{\star *}$ & $0(100 \%)^{\star \star \star}$ \\
\hline Sour milk and yoghurt & $5.1(100 \%)^{\star}$ & $8.3(99 \%)$ & $5.1(99 \%)^{\star \star \star}$ & 7.5 (99\%) & 7.9 (99\%) & 7.5 (98\%) & $4.7(100 \%)^{\star \star}$ & $0(100 \%)^{\star \star \star}$ \\
\hline Rice/pasta & $9.5(98 \%)$ & $10(98 \%)$ & $14(99 \%)^{\star \star \star}$ & $11(100 \%)$ & $11(98 \%)$ & $11(96 \%)$ & $15(100 \%)^{\star \star \star}$ & $14(100 \%)^{*}$ \\
\hline Potatoes (boiled, baked, mashed) & $14(100 \%)$ & $16(98 \%)$ & $12(100 \%)^{\star \star \star}$ & $15(99 \%)$ & $16(98 \%)$ & $18(100 \%)$ & $9.3(100 \%)^{\star \star \star}$ & $9.6(100 \%)^{\star \star}$ \\
\hline Fried potatoes & $5.0(98 \%)$ & $5.0(97 \%)$ & $2.7(100 \%)^{*}$ & $3.4(100 \%)$ & $4.3(98 \%)$ & $3.0(98 \%)^{\star \star \star}$ & $3.1(100 \%)^{\star \star}$ & $4.7(100 \%)$ \\
\hline Vegetables (except potatoes) & $25(100 \%)$ & $17(97 \%)$ & $32(99 \%)^{\star \star \star}$ & $20(99 \%)$ & $19(98 \%)$ & $25(100 \%)^{\star \star}$ & $31(99 \%)^{\star \star \star}$ & $37(100 \%)^{\star \star \star}$ \\
\hline Fruits and berries & $19(90 \%)$ & $17(96 \%)$ & $23(99 \%)$ & $24(98 \%)$ & $21(97 \%)$ & $23(96 \%)$ & $20(97 \%)$ & $26(95 \%)$ \\
\hline Porridge & $3.3(98 \%)$ & $3.8(99 \%)$ & $3.8(100 \%)$ & $2.6(99 \%)$ & $3.3(99 \%)$ & $4.6(98 \%)$ & $2.5(100 \%)^{\star \star}$ & $5.1(100 \%)$ \\
\hline Cereals & $9.7(98 \%)$ & $11(99 \%)$ & $5.0(99 \%)$ & $6.1(100 \%)$ & $8.5(99 \%)$ & $7.4(98 \%)$ & $6.1(99 \%)$ & $3.6(100 \%)^{*}$ \\
\hline Bread (all kinds) $\ddagger$ & $6.5(93 \%)$ & $6.5(95 \%)$ & $4.2(97 \%)$ & $4.4(98 \%)$ & $5.5(96 \%)$ & $4.4(93 \%)^{*}$ & $5.0(99 \%)$ & $5.1(96 \%)$ \\
\hline Margarine§ & $6.3(100 \%)^{*}$ & $7.6(98 \%)$ & $6.6(100 \%)$ & $6.2(100 \%)$ & 7.0 (99\%) & $5.5(100 \%)^{\star \star}$ & $6.5(100 \%)$ & $7.8(100 \%)$ \\
\hline Coffeeף & $1.7(100 \%)$ & $5.1(98 \%)$ & $4.2(99 \%)^{\star}$ & $2.1(99 \%)$ & $3.7(99 \%)$ & $2.3(100 \%)$ & $4.5(100 \%)$ & $3.1(96 \%)$ \\
\hline Teaף & $11(100 \%)$ & $7.6(97 \%)$ & $15(100 \%)^{\star \star \star}$ & $7.6(98 \%)$ & 7.7 (97\%) & $11(100 \%)$ & $13(100 \%)^{\star \star}$ & $22(100 \%)^{\star *}$ \\
\hline Soft drinks & $15(100 \%)$ & $16(97 \%)$ & $5.9(99 \%)^{\star \star \star}$ & $9.7(98 \%)$ & $13(97 \%)$ & $8.6(100 \%)^{\star \star}$ & $8.5(99 \%)^{\star \star \star}$ & $7.9(100 \%)^{\star}$ \\
\hline Diet soft drinks & $0.7(100 \%)$ & $2.3(96 \%)$ & $1.7(99 \%)^{\star \star}$ & $3.2(98 \%)$ & $2.9(97 \%)$ & $1.3(98 \%)$ & $1.6(100 \%)$ & $0.9(100 \%)$ \\
\hline Alcoholic beverages & $2.1(98 \%)$ & $2.2(97 \%)$ & $2.0(100 \%)$ & $1.6(96 \%)$ & $1.9(97 \%)$ & $1.7(98 \%)$ & $1.9(100 \%)$ & $2.8(100 \%)$ \\
\hline Chips, peanuts & $8.6(98 \%)$ & 9.9 (97\%) & $4.1(99 \%)^{\star \star \star}$ & 6.8 (99\%) & $8.4(98 \%)$ & $4.3(96 \%)^{\star \star \star}$ & $5.5(100 \%)^{\star \star \star}$ & $7.0(100 \%)$ \\
\hline Ice cream & $4.9(98 \%)^{* *}$ & $7.6(96 \%)$ & $5.4(98 \%)$ & $5.1(99 \%)$ & $6.4(97 \%)$ & $4.0(96 \%)^{\star \star}$ & $6.2(99 \%)$ & $4.9(100 \%)$ \\
\hline Cakes, cookies & $7.2(98 \%)^{\star}$ & $10(97 \%)$ & $5.9(100 \%)^{\star \star}$ & $7.4(99 \%)$ & $8.8(98 \%)$ & $4.5(98 \%)^{\star \star \star}$ & $8.2(100 \%)$ & $3.6(100 \%)^{\star \star \star}$ \\
\hline Sweets, chocolates & $16(100 \%)$ & $15(97 \%)$ & $13(100 \%)$ & $13(99 \%)$ & $14(98 \%)$ & $12(100 \%)$ & $15(100 \%)$ & $16(100 \%)$ \\
\hline Fast foods & $8.7(88 \%)$ & $12(88 \%)$ & $2.4(86 \%)$ & $6.1(87 \%)$ & $9.1(88 \%)$ & $4.4(82 \%)^{\star \star}$ & $4.3(90 \%)$ & $3.1(82 \%)$ \\
\hline Fried food & $13(98 \%)^{\star}$ & $17(99 \%)$ & $11(98 \%)^{\star \star \star}$ & $15(99 \%)$ & $16(99 \%)$ & $13(96 \%)$ & $11(99 \%)^{\star \star \star}$ & $13(100 \%)$ \\
\hline Barbecued food\| & $5.1(98 \%)^{\star \star \star}$ & 12 (99\%) & $4.1(98 \%)^{\star \star \star}$ & 9.5 (99\%) & $11(99 \%)$ & $6.4(96 \%)^{\star \star \star}$ & $3.0(99 \%)^{\star \star \star}$ & $3.6(100 \%)^{\star \star \star}$ \\
\hline Microwave-heated food†† & $12(100 \%)$ & $9.6(99 \%)$ & $11(98 \%)^{*}$ & $7.4(99 \%)$ & $8.5(99 \%)$ & $11(98 \%)$ & $12(99 \%)$ & $11(100 \%)$ \\
\hline 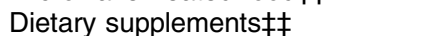 & $5.5(78 \%)$ & $1.9(67 \%)$ & $6.2(88 \%)^{*}$ & $2.1(71 \%)$ & $2.0(69 \%)$ & $4.4(75 \%)^{*}$ & $5.3(92 \%)^{\star \star \star}$ & $12(91 \%)^{\star \star *}$ \\
\hline
\end{tabular}

$\dagger$ Unless otherwise indicated, figures show frequency rate (times/month) of consumption of a given food item; percentages in parentheses represent response rate to the question. Comparisons between dietary groups were made separately for both genders and for each of the vegetarian groups, as compared with the omnivores, by the Mann-Whitney non-parametric U-test.

$¥$ The data given present slices of bread per day.

$\S$ Grams per slice of bread.

I) Cups per month.

$\|$ During the summer months.

t† Both ready foods that are bought in the supermarket and home-made food.

$\neq \neq$ Number of pills per week.

* Significantly different from omnivores $(P \leq 0.05)$

** Significantly different from omnivores $(P \leq 0.01)$. 
important in adolescence because of rapid physiological changes $^{22}$. Adolescence is a period of life when values form and increasing autonomy and self-identification are being developed ${ }^{4}$. The eating patterns of adolescents may differ from those of their families and mainstream habits. During this process, friends, peer leaders, idols and philosophies/movements such as the Straight Edge philosophy and animal liberation organisations may have strong influences in various ways, including food choice.

The results of the present study show that the stricter the vegetarian diet, the more often were dietary supplements being used and the stronger was the subject's wish for more information on healthy eating. A possible explanation for this is that the stricter vegetarians are more concerned about not getting an adequate amount of nutrients. The result may indicate that the young vegetarians in the present study were uncertain about the adequacy of their diet, which may more often be the case when a vegetarian diet is chosen for ethical reasons than if it is followed for health reasons. Another explanation may be that taking nutrient supplements is relatively easy compared with making extensive modifications of one's diet and many subjects therefore focused on supplements rather than changing their dietary habits $^{23}$. Our finding that there was more frequent use of supplements among female vegetarians (Table 4) is consistent with the results of another questionnaire study comparing the health practices of vegetarians and omnivores $^{24}$. In that study vegetarians felt that their nutritional knowledge and practices, as well as diet, were satisfactory $^{23}$, while $29 \%$ of the female vegetarians in the present study perceived their dietary intake to be inadequate (23\% felt it was adequate) (Table 2). On the other hand, the present study showed that more vegetarians than omnivores expressed the wish to find out more about the importance of diet to good health (Table 2). A possible explanation is that young vegetarians either lack knowledge of a nutritious vegetarian diet or have a greater interest in diet and health than omnivores. If dieting issues had been taken into consideration this result may have been explained by a greater interest in dieting. However, there were no significant differences in opinion about weight (data submitted) between vegetarians and omnivores of either gender. Vegetarian and vegan males in our study more often derived information about the importance of diet from newspapers/magazines/brochures or several different sources while omnivores obtained it mainly from their parents or school (Table 2). A possible explanation for this is that diet and health education in schools rarely discusses aspects of vegetarianism. This results in young vegetarians looking for information published by the media or vegetarian organisations, although many (31$32 \%$ ) expressed an interest in getting more health- and diet-related information from school.
In this study the vegetarian subjects, especially the lacto-(ovo)-vegetarians, ate breakfast and dinner with their family less frequently than did their omnivorous peers (Table 3). As previously mentioned, these results may be interpreted differently if dieting issues are taken into consideration. The adolescent vegans also ate their dinner with the family less frequently than the omnivores (Table 3) but no significant difference between the two groups was seen for breakfast. Reasons for eating dinner with the family less frequently may be that when you are a vegan it is more difficult to eat the same meal that the omnivorous family members are eating. In cases where the parents do not support the adolescent's vegetarian choice, the situation becomes even more difficult. In those cases the vegan adolescents may have to prepare their own meal, which sometimes happens at odd hours. Often this results in taking the meal alone rather than with the rest of the family. If the vegetarian lunch served at school was not tasty some of the vegans seemed to prefer eating sweets or nothing at all, which illustrates the importance of available, nutritious and tasty vegetarian food alternatives in school.

\section{Frequency of food intake}

In the present study we have measured the frequency of food intake; previous studies have shown that food intake frequency correlates well with food intake $\left(\mathrm{g} \mathrm{day}^{-1}\right)$ at a group level ${ }^{15,25,26}$. The same statistically significant difference in food intake frequency pattern and food intake $\left(\mathrm{g} \mathrm{day}^{-1}\right.$ ), between a lacto-vegetarian diet and an omnivorous diet, was seen when using a food intake frequency questionnaire as when repeated 24-hour recalls $^{25}$ or diet records were used ${ }^{26}$. Therefore it is likely that the differences in food intake frequency presented in the present study represent actual differences in food intake frequency between vegetarians and omnivores.

Consumption frequencies of cereals, bread and fruits of vegetarians and omnivores were consistent with the results of an Australian questionnaire study of 2000 adolescents (mean age 16 years), which showed no significant differences between young vegetarians and omnivores regarding consumption of cereal, bread, apples and bananas $^{16}$. However, in other studies of adolescents (12-20 years old), young vegetarians, in comparison with omnivores, had a higher consumption of fruits and a relatively low intake of sweets and salty snack foods. The young vegetarians in the present study ate fruits/berries and sweets/chocolates to the same extent as the omnivores (Table 4$)^{4,27}$. On the other hand, the vegetarian females in the present study reported less frequent intake of chips/peanuts, soft drinks and cakes/ cookies than the omnivores (Table 4), which is likely to have given their diet a higher nutrient quality. The vegetarians also ate fried and barbecued food less often than the omnivores (Table 4). A possible explanation is that most barbecued food is of animal origin and that 
barbecues may be contaminated with animal products. Since in the present study there was no weight difference between the vegetarian and omnivorous adolescents, the significantly lower consumption frequency of some of the reported food items will have to have been compensated, either by the higher consumption of rice/pasta and vegetables by females or by a higher consumption frequency of food items not included in the questionnaire, larger portions and/or less physical activity compared with omnivores. The results of the comparison of young vegetarians' and omnivores' food habits in the present study differ in some respects from previously published comparative studies of vegetarians' and omnivores' food habits. Previous studies of vegetarians have shown that this dietary group consumes cereals, bread and fruits/berries more often than omnivores ${ }^{15,28,29}$. However, the vegetarians in the present study consumed these food items as often as the omnivores (Table 4). Another contrast between this and previous studies of vegetarians is that in previous studies vegetarians were found to consume coffee, alcoholic beverages, sweets and junk food less often than omnivores ${ }^{15,24,27-32}$, while the young vegetarians in the present study consumed these items more often than or just as often as the omnivorous adolescents. These contradictory results indicate that most likely health was not the major reason why the young vegetarians in the present study became vegetarian. Several studies indicate that ethical concerns appear to be the main motivation for vegetarianism among young people of today ${ }^{4-7}$. The question is whether the health benefits shown in previous studies of vegetarians will apply to the new generation of vegetarians ${ }^{11-13}$.

\section{Conclusion}

During the 1990s the reason for being vegetarian appears to have shifted towards ethical concerns ${ }^{5,6,8,16,20}$. In the present study vegetarianism among adolescents was seen to be more than three times as common in Umeå than in Stockholm and Bergen. The food habits of the young generation of vegetarians covered a wide range of eating styles and differed from the food habits of omnivorous adolescents; in some respects they also differed from what has previously been published about vegetarians. While the vegetarian males in the present study more or less excluded animal products without changing their food habits in other respects, the vegetarian females more often consumed vegetables and took dietary supplements. However, there were no differences between the two dietary groups in the intake of fruits/berries, alcoholic beverages, ice cream, sweets/chocolates and fast foods. It remains to be seen whether the health benefits shown in previous studies of vegetarians will apply to the new generation of vegetarians, as they grow older. Information on vegetarian adolescents' nutrient intake and nutritional status is limited; however, vegetarianism in adolescents is extremely important to monitor since each generation of vegetarians have their own priorities, problems and health benefits.

\section{Acknowledgements}

The authors would like to thank all of the students who participated, Inger Öhlund, Linda Hagfors and Maria Larsson for valuable help with data entry, Mats Nilsson for statistical advice, AB PT Datatech Systems Sweden, Peter Tanskanen and Seppo Salonen for skilful computer help. The study was supported financially by the Swedish Foundation for Healthcare Science and Allergy Research, the Swedish Nutrition Foundation, the Research Foundation of Bertil Eriksson, the Fund of Uppsala Hemsysterskola, the JC Kempes Memorial Fund, and the Swedish Patent Revenue Research Fund.

\section{References}

1 White R, Frank E. Health effects and prevalence of vegetarianism. West. J. Med. 1994; 160: 465-71.

2 Larsson C, Johansson G. Prevalence of vegetarians in Swedish secondary schools. Scand. J. Nutr. 1997; 41: 117-20.

3 Frost Andersen L. Personal communication concerning UNGKOST-93 conducted in 1993, Institute for Nutrition Research, Oslo, Norway, 1999.

4 Neumark-Sztainer D, Story M, Resnich M, Blum RW. Adolescent vegetarians. Arch. Pediatr. Adolesc. Med. 1997; 151: $833-8$.

5 Kenyon P, Barker M. Attitudes towards meat-eating in vegetarian and non-vegetarian teenage girls in England an ethnographic approach. Appetite 1998; 30: 185-98.

6 Santos M, Booth D. Influences on meat avoidance among British students. Appetite 1996; 27: 197-205.

7 Kim EH, Schroeder KM, Houser RF, Dwyer JT. Two small surveys, 25 years apart, investigating motivations of dietary choice in 2 groups of vegetarians in the Boston area. J. Am. Diet. Assoc. 1999; 99: 598-601.

8 Worsley A, Skrzypiec G. Teenage vegetarianism: beauty or the beast? Nutr. Res. (New York) 1997; 17: 391-404.

9 Martins Y, Pliner P. Restrained eating among vegetarians: does a vegetarian eating style mask concern about weight? Appetite 1999; 32: 145-54.

10 White R, Seymour J, Frank E. Vegetarianism among US women physicians. J. Am. Diet. Assoc. 1999; 99: 595-8.

11 Key TJ, Fraser GE, Thorogood M, Appleby PN, Beral V, Reeves G, Burr ML, Chang-Claude J, Frentzel-Beyme R, Kuzman JW, Mann J, McPherson K. Mortality in vegetarians and nonvegetarians: detailed findings from a collaborative analysis of 5 prospective studies. Am. J. Clin. Nutr. 1999; 70: $516 \mathrm{~S}-24 \mathrm{~S}$.

12 Dwyer JT. Health aspects of vegetarian diets. Am. J. Clin. Nutr. 1988; 48: 712-38.

13 Dwyer JT. Nutritional consequences of vegetarianism. Annu. Rev. Nutr. 1991; 11: 61-91.

14 Sabate J. Nut consumption, vegetarian diet, ischemic heart disease risk, and all-cause mortality: evidence from epidemiologic studies. Am. J. Clin. Nutr. 1999; 70: 500S-3S.

15 Johansson $G$, Callmer E, Gustafsson J-A. Changing from a mixed diet to a Scandinavian vegetarian diet: effects on nutrient intake, food choice, meal pattern and cooking methods. Eur. J. Clin. Nutr. 1992; 46: 707-16. 
16 Worsley A, Skrzypiec G. Teenage vegetarianism: prevalence, social and cognitive contexts. Appetite 1998; 30: 151-170.

17 ADA Reports. Position paper on the vegetarian approach to eating. J. Am. Diet. Assoc. 1980; 77: 61-9.

18 Ratzin R. Nutritional concerns for the vegetarian recreational athlete. In: Ratzin Jackson C, ed. Nutrition for the Recreational Atblete. Boca Raton, FL: CRC Press, Inc., 1995: 93-110.

19 Neumark-Sztainer D, Story M, Perry C, Casey MA. Factors influencing food choices of adolescents: findings from focus-group discussions with adolescents. J. Am. Diet. Assoc. 1999; 99: 929-37.

20 Beardsworth A, Keil E. Vegetarianism, veganism and meat avoidance: recent trends and findings. Br. Food J 1991; 93 $19-24$.

21 Bergström E. Cardiovascular risk indicators in adolescents. the Umea youth study. Doctoral thesis, Umeå University, Sweden, 1995.

22 Lifshitz F, Tarim O, Smith MM. Nutrition in adolescence. Endocrinol. Metab. Clin. North Am. 1993; 22: 673-83.

23 Messina V. Popular perceptions of vegetarian diets: is the pendulum swinging the other way? [comment]. Vegetarian Nutr. 1998; 2: 37-9.

24 Freeland-Graves J. Health practices, attitudes, and beliefs of vegetarians and nonvegetarians. J. Am. Diet. Assoc. 1986; 86: $913-8$

25 Midtvedt T, Johansson G, Carlstedt-Duke B, Midtvedt A, Norin K, Gustafsson J. The effect of a shift from a mixed to a lacto-vegetarian diet on some intestinal microflora associated characteristics. Microbial Ecol. Health Dis. 1990; 3: 33-8.

26 Ảkesson A. Cadmium exposure and iron status. Doctoral thesis, Karolinska Institute, Stockholm, Sweden, 2000.

27 Donovan UM, Gibson RS. Dietary intakes of adolescent females consuming vegetarian, semi-vegetarian, and omnivorous diets. J. Adolesc. Health 1996; 18: 292-300.

28 Hardinge M, Crooks H. Non-flesh dietaries: adequate and inadequate. J. Am. Diet. Assoc. 1964; 45: 537-42.

29 Outila T, Kärkkäinen M, Seppänen R. Food and nutrient intake of premenopausal female vegetarians and omnivores in Finland. Scand. J. Nutr. 1998; 42: 98-103.

30 Dwyer JT. Vegetarian eating patterns: science, values, and food choices - where do we go from here? Am. J. Clin. Nutr. 1994; 59(Suppl.): 1255S-62S.

31 Pribs P, Sabate J, Fraser G. Food consumption among vegetarians and nonvegetarian California Seventh-Day Adventists, 1994-1996. Am.J. Clin. Nutr. 1999; 70: 633S-4S.

32 Johnston P, Haddad E, Sabate J. The vegetarian adolescent. Adolesc. Med. 1992; 3: 417-37. 